\title{
A FACTOR-AUGMENTED VECTOR AUTOREGRESSIVE APPROACH TO ANALYSE THE TRANSMISSION OF MONETARY POLICY
}

\section{Zulfiqar Ali Wagan, Zhang Chen, Hakimzadi Wagan*}

\begin{abstract}
Using the factor-augmented vector autoregressive (FAVAR) model proposed by Bernanke et al. (2005), this study explores the effect of monetary policy on a wide range of macroeconomic and financial variables for the US, Canada and the UK. The study makes use of financial data from 1990 to 2016, comprising 55-70 variables of the three major nations to show (1) that factors come with additional informational capability, which summarizes the performance of key macroeconomic variables and (2) the manner in which these variables are affected by contractionary monetary policies. Our findings confirm that monetary policy tightening results in decrease in industrial production, employment, share prices, housing starts and inflation; however, it leads to increase in the three-month treasury bill rate, long-term interest rates and unemployment. Overall, the impact of standardized monetary tightening is similar across the countries studied. These results from the major economies and the inclusion of larger data sets containing more variables would be relevant for policy theorists and practitioners from other countries.
\end{abstract}

Keywords: monetary policy, FAVAR, VAR, Bayesian methods

JEL Classification: C11, E40, E52

\section{Introduction}

The past 35 years have witnessed substantial work and a huge advancement in the area of stationary vector auto- regressions (VARs). ${ }^{1}$ It would not be wrong to say that the empirical analysis of stationary VARs is almost complete. VARs, popularly known as workhorse models, have become the benchmark for analysing the impact of monetary policy transmission (Christiano et al., 1999). Despite the advancement made, it is observed that VAR models have limitations as regards their use for the practical aspects of monetary policy making. The shortcomings include the identification problem and the use

* Zulfiqar Ali Wagan, Hefei University of Technology, School of Management, Hefei, China and Education and Literacy Department, Karachi, Pakistan (zulfiqarsch@mail.hfut.edu.cn); Zhang Chen, Hefei University of Technology, School of Management, Hefei, China (mszhangchen@hfut.edu.cn); Hakimzadi Wagan, Sindh Agriculture University, Faculty of Social Sciences, Tando Jam, Pakistan (hakimzadi@gmail.com).

We thank anonymous reviewers for their constructive comments and suggestions, which helped us to improve the manuscript. This work has been fully supported by the National Natural Science Foundation of China under grant number 71373065.

1 VAR was initially proposed by Sims and Christopher (1980) three decades ago to address four macro-econometric tasks: data description and summarization; macroeconomic forecasting; structural inference; and macroeconomic policy analysis. 
of an insufficient number of variables - usually three or four, very rarely more than $10^{2}$ and VAR models are subject to Lucas critique. Consequently, the use of these models in monetary policy decision making at central banks is limited.

Different approaches have been proposed by researchers but the common concept underlying most of them is that of shrinkage. ${ }^{3}$ The approach could involve the shrinking of parameters towards zero or imposing restrictions on them. For this purpose, Bayesian methods offer the best solution in using prior information to shrink parameters. Building a model by using hundreds of time series variables is a challenging task, raising problems related to the potential proliferation of parameters and the need for methods to reduce the dimensionality of the model. Factor methods provide a solution by analysing the information contained in hundreds of variables and replacing them by a few factors.

Later on, static factor models were developed into dynamic factor models (DFMs) to resolve the issue of identification. With the help of DFMs, researchers are able to explain the changes in a large set of cross-sectional data with the help of only a few common shocks, such as monetary policy, news, technology, fiscal policy and oil shocks, which depict the key dynamics. The pioneering work was done by Geweke (1977), and the applications were suggested by Stock and Watson (2002). Combining factor methods with VARs leads to factoraugmented VARs (FAVARs), which were introduced by Bernanke et al. (2005). The basic idea was to resolve the dimensionality problem by imposing restrictions derived from the DFM.

Questions related to monetary policy tightening and the transmission of policy shocks have always remained a core area for researchers and they have tried different ways to answer them (see, e.g., Bernanke and Gertler, 1995; Rabanal, 2007; Lamb, 2016). The studies can be categorized according to whether they focused on the qualitative or quantitative effects of monetary policy. The studies in the former category try to answer the questions using theoretical approaches, such as those used by Boivin and Giannoni (2006) or Justiniano and Primiceri (2008). Compared with the qualitative studies, there is less unanimity among the quantitative researchers. Much empirical work has been done on quantitative effects of monetary policy by Sims (1992), Sims and Zha (2006) and Bruno and Shin (2015), among others.

Many researchers followed the lead of Sims (1992) and tried to answer the main questions using VAR. Rapid progress has been made over the past 25 years. The "price puzzle" anomaly, raised by Sims (1992), and other issues, motivated the inclusion of the commodity price index, output gap, composite leading indicator of economic activity, expected inflation under indeterminacy, the use of sign-restricted VAR models, and imposing long-run restrictions in VAR studies (see, e.g., Bjørnland and Jacobsen, 2010; Castelnuovo and Surico, 2010; Lanne and Luoto, 2016).

Cross-country comparisons to study the effects of monetary policy were initiated at the Bank for International Settlements by Gerlach and Smets (1995). A growing number

2 The study by Banbura et al. (2010) is an exception to this because it uses Bayesian VAR, which has up to 130 variables.

3 Macroeconomists normally use hierarchical priors or empirical Bayesian. An example of hierarchical prior is the state equation in a state space model. 
of studies have paid attention to the cross-country effects of monetary policy. They include Bjørnland and Halvorsen (2014) and Nocera and Roma (2017).

There are two schools of thought regarding the impact of contractionary monetary policy on business cycle fluctuations, particularly with reference to output and inflation. For instance, how inflation will respond to an increase in interest rates depends on whether the economic conditions are favourable to implementing an inflation targeting regime or not. The monetary policy neutrality view is represented by Bjørnland and Jacobson (2010), who find that shocks to monetary policy do not have long-run effects on economic activity. On the other hand, Korenok and Radchenko (2004), who studied the permanent and transitory measures of cyclical fluctuations to examine monetary policy effects on the business cycle for the US, find that monetary policy shocks have a permanent effect on economic activity.

It seems that the main issue is one of the size of these shocks rather than their duration. How large are the effects of monetary policy shocks? The answer from the current state of the literature is mixed, with monetary VARs commonly pointing to small effects of monetary policy shocks (and nominal contribution of these shocks to historical US macroeconomic fluctuations) while the Taylor rule approach of Romer and Romer (2004) implies much larger effects of monetary shocks, for both historical decompositions and impulse responses. Coibion (2012) supports the broader claim of Romer and Romer (2004) that monetary policy innovations are historically significant and differs with the prediction of standard VARs that monetary policy shocks have mattered little for historical US macroeconomic fluctuations.

Bernanke et al. (2005) evaluated the impact of monetary policy on US macroeconomic variables. They deployed as many as 120 monthly macroeconomic data in a time series between 1959 and 2003, employing a FAVAR and a VAR model. After extracting some common factors from the data, they used it with the federal fund rate in the form of a policy variable within the FAVAR model. They also employed two distinct methodologies for estimating the FAVAR: Bayesian 6 method premised on Gibbs sampling, and the twostep principal component approach. They then compared the findings of both models and concluded that the FAVAR model did not entail any price puzzle. They added that the output response was congruous with the theory of a surge of federal funds rate; on the other hand, the VAR model demonstrated a strong price puzzle.

Lagana and Mountford (2005) assessed the effect of monetary policy on several macroeconomic variables across the UK and utilized the FAVAR and VAR model. According to their main findings, a contractionary monetary policy is correlated with an increase in stock market and housing prices, whereas it causes a depreciation of the pound (UK) with regard to the US dollar. They observed that the additional factors to the VAR (FAVAR) model produce better results than the benchmark AR and VAR models.

In the existing literature, the VAR model has been used as a powerful research tool to quantify the effects of monetary policy shocks; however, structural VAR has been widely criticized on three grounds, given below.

First, it suffers from the omitted variable bias. Central bankers normally consider a large number of variables to make policy decisions based on qualitative as well as quantitative analysis. The absence of these variables in a VAR model results in a shock 
known as the "price puzzle" in VAR literature (Bjørnland and Jacobsen, 2010; Bishop and Tulip, 2017). The second issue pertains to the misspecification in constant coefficient VAR models, such as the three-variable VARs, when the policy rules change over a period of time. In this regard, the work of Sims and Zha (2006) and Ang et al. (2011) is worth mentioning.

The third issue relates to the identification of assumptions that inflation and output would respond within a given period. Such assumptions seem reasonable for changes over a day, but not over a month or quarter. Attempts have been made in the literature to resolve this issue by assuming that monetary policy shocks can have no long-run effect on the real stock prices, real exchange rate and real gross domestic output (Bjørnland and Leitemo, 2009). Researchers have tried to resolve all these issues by using factors to extract information from data sets with many variables. Over a ten-year period, researchers have developed models, such as the generalized or approximate DFM, with the aim of processing large quantities of data (Stock and Watson, 2002; Korobilis, 2013).

The Factor Augmented VAR (FAVAR), which is an extension of the DFM with an implicit restriction, permits impulse response analysis that is more economically sensible. Studies such as Stock and Watson (2005) or Bernanke et al. (2005) combine factor methods with VARs. In general, the FAVAR approach is superior to VAR because it provides a comprehensive view of the effects of monetary policy, and may be more intuitive for policy makers due to the following reasons. First, standard VAR requires an explicit connection between the variable used and the theoretical concept it represents. For example, it is common practice to use industrial production or gross domestic product (GDP) as the measure of "economic activity." However, there may be a mismatch between the variable for which data are available and the theoretical construct it measures or represents. Hence, some variables need to be treated as unobserved at the time of deciding monetary policy interventions. The FAVAR approach allows this. Second, it allows central bankers to analyse the rich data set at the time of monetary policy making. The central banks or agents on financial markets possess bigger chunks of information compared to the information set contained in the VAR model; as a result, there is a strong likelihood that the measurement relating to policy shocks will get contaminated. This in turn could be attributed to the inherent omitted variable bias across VAR models that are of a smaller size (Breitung and Eickmeier, 2005). The "price puzzle" is one instance of this policy analysis. The price puzzle generally entails the findings of VAR models wherein the prices rise as a result of contractionary monetary policy. One plausible rationale often given for this price puzzle is that the VAR model is unable to capture the larger information set available to the central banks (Sims, 1992). Therefore, the FAVAR approach provides a better solution to this problem. Third, standard VAR allows the observation of impulse responses for only the limited variables included in the model, which generally is a tiny fraction of variables which would be of interest to both researchers and policy makers. In order to evaluate the effect of policy alterations on economic activity, there is a need to examine factors such as sales, employment, hourly earnings, inventory changes, the number of hours worked in a week, durable goods consumption, consumer confidence, capacity utilization and the GDP or IP, whereas in the FAVAR approach, one can work with 
hundreds of the variables and observe the impulse response functions for each of them. The FAVAR is the solution for better data fit and better forecasting properties. The model does not necessarily provide better impulse responses to monetary policy shocks. Therefore, the FAVAR is superior to the VAR in terms of forecasting performance. At the same time, the authors admit that in the text and take it as a presumption.

This study differs from previous ones in studying the transmission of monetary policy not only in the US, but also in Canada and the United Kingdom. It uses the FAVAR approach and extensive data sets for each country to test its efficacy in resolving the issues mentioned above.

We use the Bayesian framework for estimation of the FAVAR model because of its efficiency in using the information for the purpose of inference as well as decision making with this econometric model. In the case of nonlinear models, data augmentation techniques are needed to cope with quantitative issues associated with hidden state variables, such as in regime-switching models and VAR with time-varying coefficients. Keeping all this in view, we expect to better capture the impulse responses to monetary policy shocks. In addition, the FAVAR approach supports the calculation of the impulse response functions for all the variables that are included in the data set and helps in studying the effect of monetary policy on the economy.

This paper contributes to existing literature by making an extensive cross-country investigation covering the US, Canada and the UK, using the FAVAR approach under a Bayesian framework. ${ }^{4}$ We use percentiles to construct error bands to make precise inferences, based on Cogley and Sargent (2005), who criticize the conventional approach of building an error band on the basis of " $1-\alpha$ ". They argue that such a band does not encompass the region that contains the true impulse response having the probability of $1-\alpha$ and does not provide sufficient information about the forms of deviation from the point estimate of an impulse response function.

Our findings confirm that monetary policy tightening results in decrease in industrial production, employment, share prices, housing starts and inflation; however, it leads to increase in the three-month treasury bill rate, long-term interest rates and unemployment.

The rest of the paper is structured as follows. Section 2 describes the empirical framework and model, Section 3 provides details about the data and sources. Sections 4 presents the empirical results and discussion and Section 5 concludes.

\section{Econometric Framework}

\subsection{FAVAR model}

This section provides the framework for the FAVAR methodology that aims to eliminate the drawback of the sparse information set used in VAR analysis. Bernanke et al. (2005)

$4 \quad$ Our study initially targeted all the G-7 countries. However, sufficient data was not found for all the categories of variables, and in the case of some categories, the time period was too short to draw consistent conclusions. 
introduced the FAVAR for estimating the factors that describe the most of the information content of large data sets. ${ }^{5}$ Let $X_{t}$ be a $(\mathrm{N} \times 1)$ vector of rich "informational" time series variables. $^{6}$

Let $Y_{t}$ be a $(\mathrm{M} \times 1)$ vector of observable time series macroeconomic variables, assumed to have persistent effects on the economy. However, in many instances, additional information is required to depict the dynamics of the series not fully explained by $Y_{t}$. As $Y_{t}$ contains the policy instrument and (possibly containing other policy variables not contained in $X_{t}$ ) other observable measures of inflation and economic activity, it can be considered a subset of $X_{t}$. In most VAR analyses, a limited number of variables (normally four to eight) are used for estimation. The additional variables required to depict the dynamics can be written as $F_{t}$, where $F_{t}$ is the $(\mathrm{K} \times 1)$ vector of unobserved factors. According to Bernanke et al. (2005), "we might think of the unobserved factors as diffuse concepts, such as 'economic activity' or 'credit conditions' that cannot be easily represented by one or two series but rather are reflected in a wide range of economic variables".

To depict the dynamics of observed and unobserved factors to identify monetary policy shocks, we use the same model as proposed by Bernanke et al. (2005) which is given by:

$$
\left[\begin{array}{l}
F_{t} \\
Y_{t}
\end{array}\right]=\Phi(L)\left[\begin{array}{l}
F_{t}-1 \\
Y_{t}-1
\end{array}\right]+v_{t} .
$$

Where $\Phi(L)$ is a lag polynomial of the finite order $d$ and the error term $v_{t}$ is identically and independently distributed, with mean zero and with the covariance matrix $Q$.

It is possible to reduce the above system to standard VAR, if the terms of $\Phi(L)$ that relate $Y_{t}$ to $F_{t}$ are zero. The system described above enables one to assess the marginal contribution of additional information in $F_{t}$. Unlike the FAVAR models, the standard VAR suffers from omitted variables bias; hence, the FAVAR is a more realistic depiction of economic dynamics and produces better results than the VAR model. The addition of factors eliminates the downside of a sparse information set found in VAR models.

\subsubsection{Identification of the FAVAR}

The FAVAR model in Equation (1) cannot be estimated since the factors are not observed. As $F_{t}$ is assumed to represent the information contained in $X_{t}$, it is possible to extract some information about $X_{t}$ from the data. The following relation between $X_{t}$ and $F_{t}$ is assumed:

$$
X_{t}=\Lambda^{f} F_{t}+\Lambda^{y} Y_{t}+\varepsilon_{t}
$$

$5 \quad$ See Stock and Watson $(2002,2005,2016)$ or Bernanke et al. (2005).

6 In standard VAR models, it is important to consider co-integration among non-stationary variables to check whether the Vector Error Correction Autoregressive model is pertinent. In FAVAR models, this issue does not exist because of the use of factors rather than variables. Every factor employed in VAR is orthogonal; therefore, co-integration is not supposed to exist among the factors. 
Where $\Lambda^{f}$ is an $(N \times K)$ matrix, $\Lambda^{y}$ is a $(N \times M)$ matrix of factor loadings, and $\varepsilon_{t}$ is an error term of the dimension $(\mathrm{N} \times 1)$. Stock and Watson (2005) referred to the above equation as to a factor model. ${ }^{7}$

We perform principal component analysis following Bernanke et al. (2005) by using all the variables in $X_{t}$ to get the first $\mathrm{K}+\mathrm{M}$ principal components that can be denoted as $\hat{C}\left(F_{t}, Y_{t}\right)$. It is necessary to remove the dependence of $\hat{C}\left(F_{t}, Y_{t}\right)$ on $Y$, because the estimated factors are a part of the space that is covered by $\hat{C}\left(F_{t}, Y_{t}\right)$ but not covered by $Y_{t}$. For this, we perform the following steps. First, using the concept of slow-moving and fast-moving variables, we divide the series $X_{t}$ into two groups of variables. Fast-moving variables such as stock prices and interest rates are assumed to respond contemporaneously to economic news or monetary policy shocks, whereas slow-moving variables such as output, employment, average hourly earnings and price indices do not.

Then, we get a matrix of slow-moving factors, $\mathrm{C}\left(F_{t}\right)$ by using principal component analysis on slow-moving variables, and subsequently run the following regression:

$$
\hat{C}\left(F_{t}, Y_{t}\right)=\beta^{f} C\left(F_{t}\right)+\beta^{y} Y_{t}+e_{t}
$$

We get the estimated factors, $\hat{F}_{t}$, by taking the difference $\hat{C}\left(F_{t}, Y_{t}\right)-\hat{\beta} Y_{t}$. The parameters are sampled based on a final estimate of the factors, where the factors are treated as observed data.

Now, FAVAR Equation (1) can be estimated by replacing $F_{t}$ with $\hat{F}_{t}$. It is important to discuss the identification of Equations (1) and (2), and especially the restrictions needed to identify the factors and their loadings.

As in the Gibbs sampling, factors are identified by both Equations (1) and (2); hence, to ensure identification, we identify $F_{t}$ against the rotation, $F_{t}^{*}=A F_{t}-B Y_{t}$ in the next step. Here, $A$ can be defined as a $(K \times K)$ nonsingular matrix whereas $B$ can be defined as a $(K \times M)$ matrix. Leaving the VAR unrestricted, we impose restrictions on Equation (2). By substituting $F_{t}$, we get the following equation:

$$
X=\Lambda^{f} A^{-1} F_{t}^{*}+\left(\Lambda^{y}+\Lambda^{f} A^{-1} B\right) Y_{t}+e_{t} .
$$

To restrict the means by which the $Y^{\prime} s$ impact the $X^{\prime} s$, the identification of factors and their loadings needs to satisfy $\Lambda^{f} A^{-1}=\Lambda^{f}$ and also $\Lambda^{y}+\Lambda^{f} A^{-1} B=\Lambda^{y}$. We set the upper block of the $(K \times K)$ block of $\Lambda^{f}$ to an identity matrix and the upper block of $(K \times M)$ block of $\Lambda^{y}$ to zero. The choice of the block restricts the effect of $Y_{t}$ on the $K$ variables; hence, the variables chosen for the respective block should not be contemporaneously responsive to $Y_{t}$. The next step involves the identification of monetary policy innovations, which are discussed in the next section.

7 The implication of Equation (2), that $X_{t}$ depends on a current rather than a lagged value is not restrictive, $F_{t}$ can include arbitrary lags. 


\subsubsection{Estimation and identification of the VAR model}

Finally, after factor estimation, the next step is to estimate and identify the VAR model that comprises $\hat{F}_{t}$ and $Y_{t}$, as mentioned in Equation (1). All the variables, except the central bank rate, are treated as unobservable; therefore, in this case, $Y_{t}$ includes only the monetary policy instrument. For the identification assumption, monetary policy is placed last in the ordering. ${ }^{8}$ Although a researcher is free to use any of the priors discussed above, we choose the non-informative prior.

\section{Data}

The data for the analysis are taken from the following sources: Thomson Reuters' EcoWin database; US Bureau of Economic Analysis website; St. Louis Federal Reserve Bank website; OECD General Statistics; and the US Bureau of Labour Statistics website. We try to include a similar set of variables for each country to facilitate comparison. Depending on data availability, the estimation periods for the countries differ. For Canada, the estimation period is from 1991:01 to 2016:12, comprising monthly data for the 55 variables selected. ${ }^{9}$ The US data is on 70 variables during the estimation period that extends from 1990:01 to 2016:12. For the UK, the estimation period ranges from 1998:01 to 2016:12, and analyses 55 variables. All the variables in $X_{t}$ are assumed to be stationary and subject to transformation, in case they are not. All the data are standardized, that is, every variable has zero mean and unit standard deviation.

\section{Empirical Results and Discussion}

In this section, we discuss our main findings based on the model developed in Section 3.

We present our results in Figures 1-6, for the US, Canada and the UK for nine major economic and financial variables encompassing our broad data set. We use three as well as five factors for each country in order to investigate the impact in the form of impulse responses that the addition of factors has on the economy.

We use twelve lags to model the monthly data sourced by us. However, using eight lags gives the same results. Bernanke et al. (2005) show that even the use of seven lags provides the same results. In the figures, the dotted lines are the $10^{\text {th }}$ and $90^{\text {th }}$ percentiles and the posterior median is given by the solid line. As the variations in central bank rates are standardized to one standard deviation, the figures report impulse responses in standard deviation units.

Increasing the number of factors leads to more logical explanations of the reduction in industrial production and prices. The estimates based on principal component analysis use 15,000 iterations of Gibbs-related sampling, of which we discard the 5000 initial draws to ensure the quantitative measure and accuracy of results. In the FAVAR framework,

8 This identification assumption signifies that the monetary policy affects variables with a lag.

9 To save space, we do not include the details (list) of all the variables that we used for our analysis, but the list can be provided on request from the authors. 
we assume that $Y_{t}$ contains only the central bank rate. This means that it is the only variable considered to have an effect on the economy.

Assisting in the comprehension of the growth and extent of monetary policy shocks and their transmission by using the FAVAR approach, Figures 1-6 demonstrate the impulse response functions of vital economic and financial variables following interest rate hikes in the US, Canada and the UK.

In the US and the UK, a 100-basis-point hike in the interest rate as part of a restrictive monetary policy in the three-factor FAVAR model causes positive response in output immediately. Increasing the number of factors from three to five in our analysis shows that output declines immediately in US and UK. Our results are in line with previous studies that posit that the effects of a monetary policy shock may begin within months of its announcement. However, the most negative impact on output in the US, Canada and the UK is noticed during the $5^{\text {th }}, 7^{\text {th }}$ and $18^{\text {th }}$ month, respectively. The impact is significant only in the US and Canada. Our finding is in line with the theoretical constructs and qualitatively supports the findings of Kazi et al. (2013), who found that the negative response in output is because of the fact that it is a slow-moving variable. This finding can be supported by the relationship between the high interest rates and a reduction in production and employment in these countries because of diminishing aggregate demand. This is evident from Figures 2, 4 and 6, where the addition of factors helps depict a more accurate response of these variables.

Reductions in stock prices (posterior median), after a contractionary monetary policy shock, by 60, 18 and 10 per cent in the US, Canada and the UK, respectively, can be observed by our preferred specification of the FAVAR model, which has five factors. This provides qualitative data that are in line with the outcomes of the study by Bjørnland and Leitemo (2009), which is centred on short- and long-term restrictions. Compared with their study, our results are based on a larger set of quantitative data and are also more robust. ${ }^{10}$

Due to the relationship between the long-term interest rates and projected short-term rates, patterns in long-term interest rates emerge, along with the short-term ones that have been caused by the actions of a monetary authority, as shown in Figures 1-6. As a result, the user cost of capital increases and the housing demand drops, leading to a negative impact on housing construction due to the lowering of the aggregate demand for housing in the economy.

The higher short-term interest rates increase the cost of housing construction, leading to a decrease in housing activity. Thus, the supply-side effect offers another explanation for the negative impact of short-term interest rates on housing construction.

The contractionary monetary policy, in the form of higher interest rates, will reduce the demand for housing and construction, resulting in lower house prices and a lower investment in residential construction. We find that this decline in housing starts, as a response to the contractionary monetary policy, is more pronounced in the US than

10 Bjørnland and Leitemo (2009) find that "a 100-basis-point increase in the federal funds rate results in a 9-percent decline in the S\&P 500 index". 
in Canada and the UK. Claessens (2009) finds similar results in the US, on comparing it with other OECD countries.

An interesting finding that emerges from our study is that the negative response of housing starts is more pronounced than the decline in equity prices. Stock prices are generally considered far less stable than house prices, and the changes in the latter could be seen as a longer-term effect, providing further support to the argument that the housing market has a greater effect on consumption than the stock market. These findings confirm the theoretical priors provided by Mishkin (2007).

We also estimate the impulse response function of inflation to contractionary monetary policy shock and find that it takes 3,2 and 6 months in the US, Canada and the UK, respectively, for it to influence pricing.

All the studies based on US data, such as those carried out by Christiano et al. (1999), Romer and Romer (2004) and Primiceri (2005), found that it took considerable time for permanent aggregate shocks to fully affect the prices, and concluded that there is a correlation between inflation and monetary policy shocks. Our findings go some way in refuting prior evidence for explanations of business cycles, and support Bils et al. (2012), who find that the persistence of inflation in the US has abated significantly over the past two decades.

Throughout the discussion, impulse response functions give a broad indication of the effects of monetary policy shocks on macroeconomic variables, and show the importance of FAVAR methodology in capturing a vast range of additional information. Policy makers may find that the FAVAR approach, whose significance in incorporating broader data sets has been demonstrated throughout this study, offers a more comprehensive view of the impact of monetary policy. To sum up, the impact of monetary policy tightening is broadly comparable across all nations, and the results are fairly robust.

\section{Conclusion}

There is a large and growing body of literature on the impact of the transmission of monetary policy on major economic and financial variables. Using the VAR approach on limited data sets, many of the researchers in the literature attempt to illuminate historical events and the workings of monetary policy over the past 40 years. This paper posits that the relationships and co-movements of macroeconomic and financial variables are better understood by using the large data sets facilitated by the FAVAR approach. More specifically, the present research demonstrates that this approach, with its use of far broader corpuses of data than are possible in VARs, is better able to explain significant alterations in output, employment, share prices, inflation and interest rates during monetary policy ruptures. A Bayesian approach was selected, as this favours the conservative estimation of parameters and retains crucial standard aspects to avert identification issues when estimating latent factors.

Our findings confirm that monetary policy tightening results in a decrease in industrial production, employment, share prices, housing starts and inflation; however, it leads to increase in the the-month treasury bill rate, long-term interest rates and unemployment. Overall, the impact of standardized monetary policy tightening is similar across countries. 
The advantages of factor models in resolving increasingly complex questions have been proved by our findings. We argue that the drawback of factor models as atheoretical time series models is resolved by using them together with dynamic stochastic general equilibrium (DSGE) models. For example, incorporating the factors into a DSGE framework combines the advantages of using large data sets and structural economic models. This can diminish the unpredictability in variable measurements. An interesting area for further study is the use of larger data sets to study the monetary transmission mechanism, especially during financial crises such as the 2008 financial crisis.

\section{Annex 1: Data description}

The data used in this study are obtained from the following sources: Reuters EcoWin database; US Bureau of Economic Analysis website; St. Louis Federal Reserve Bank website; OECD General Statistics; and US Bureau of Labour Statistics website. The choice of the variables is made from the following group and there are minor differences in the final set chosen for each country: interest rates, employment, output, unemployment, share prices, inflation and housing starts. Variable such as rates of growth, Consumer Price Index and Industrial Production Index were found to be stationary. The codes for transformation are explained as follows: "1" represents no transformation; "2" first transformation; "4" represents logarithm; and "5" involves the first difference in the logarithm.

Following Bernanke et al. (2005), we divide the variables into fast- and slow-moving. The latter are represented by an asterisk $\left(^{*}\right)$ next to the variable, and for the sake of brevity, the table shows results only for codes 1 and 4 .

Table 1 | Data included in the factor augmented VAR model

\begin{tabular}{|l|l|c|c|c|c|}
\hline \multirow{2}{*}{ S. No. } & \multirow{2}{*}{ Description } & \multicolumn{3}{|c|}{ Data span } & \multirow{2}{*}{ T Code } \\
\cline { 3 - 6 } & & US & Canada & UK & 1 \\
\hline $\mathbf{1}$ & Industrial Production Index* & $1990: 1-2016: 12$ & $1991: 1-2016: 12$ & $1998: 1-2016: 12$ & 1 \\
\hline $\mathbf{2}$ & Employment rate* & $1990: 1-2016: 12$ & $1991: 1-2016: 12$ & $1998: 1-2016: 12$ & 1 \\
\hline $\mathbf{3}$ & Unemployment rate* & $1990: 1-2016: 12$ & $1991: 1-2016: 12$ & $1998: 1-2016: 12$ & 1 \\
\hline $\mathbf{4}$ & All-share Price Index & $1990: 1-2016: 12$ & $1991: 1-2016: 12$ & $1998: 1-2016: 12$ & 1 \\
\hline $\mathbf{5}$ & Housing starts & $1990: 1-2016: 12$ & $1991: 1-2016: 12$ & $1998: 1-2016: 12$ & 4 \\
\hline $\mathbf{6}$ & Short-term interest rate & $1990: 1-2016: 12$ & $1991: 1-2016: 12$ & $1998: 1-2016: 12$ & 1 \\
\hline $\mathbf{7}$ & Long-term interest rate & $1990: 1-2016: 12$ & $1991: 1-2016: 12$ & $1998: 1-2016: 12$ & 1 \\
\hline $\mathbf{8}$ & Consumer Price Index* & $1990: 1-2016: 12$ & $1991: 1-2016: 12$ & $1998: 1-2016: 12$ & 1 \\
\hline $\mathbf{9}$ & Central bank rates & $1990: 1-2016: 12$ & $1991: 1-2016: 12$ & $1998: 1-2016: 12$ & 1 \\
\hline
\end{tabular}

Source: Authors' research 


\section{Annex 2: Figures}

Figure 1 | The US impulse response functions to Federal Funds Rate (FFR), generated from FAVAR ( $Y=F F R, 3$ factors); the dotted lines are the 10th and the 90th percentiles and the posterior median is given by the solid line.

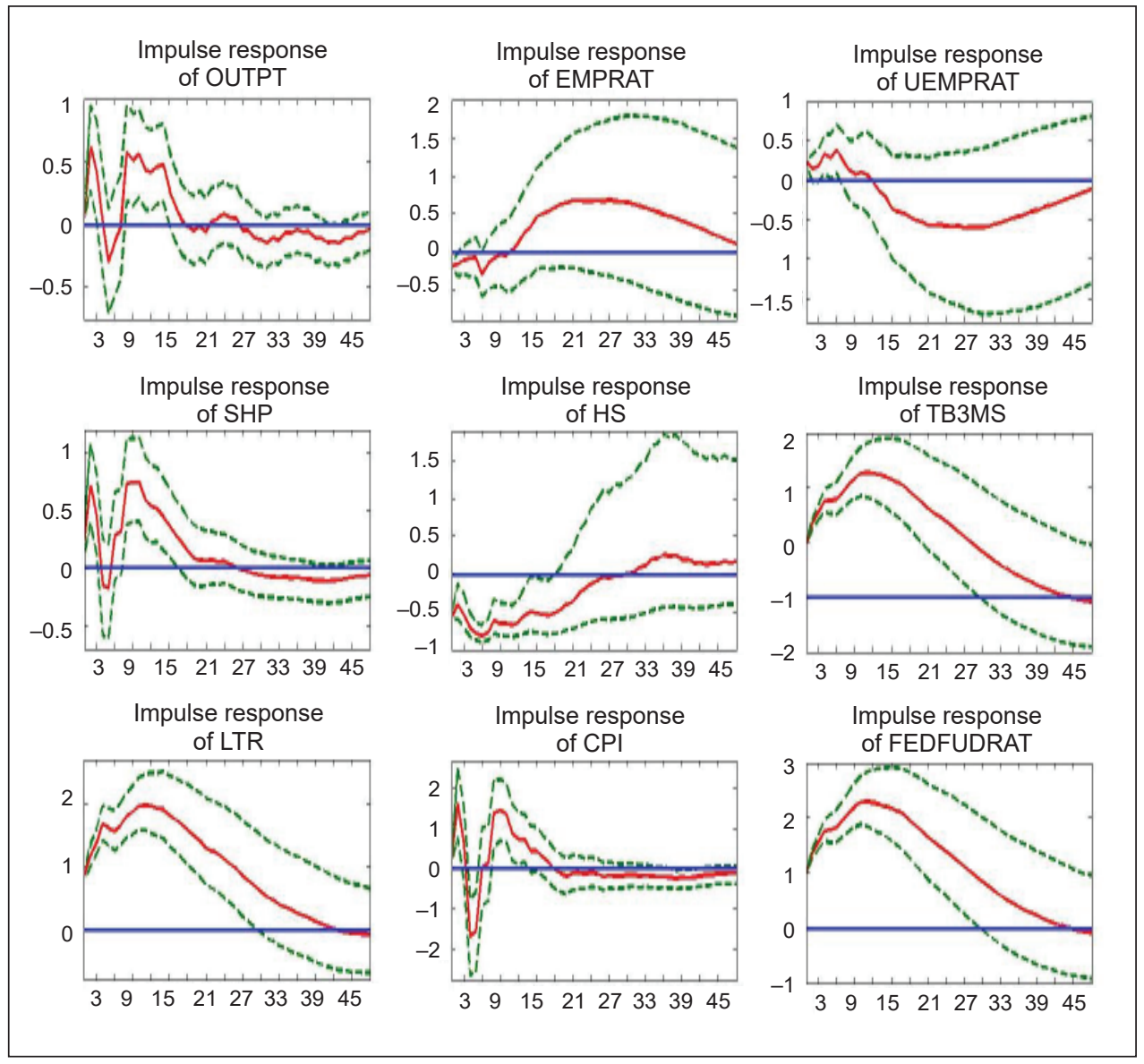

Source: Authors' calculations 
Figure 2 | The US impulse response functions to Federal Funds Rate (FFR), generated from FAVAR ( $Y=F F R ; 5$ factors); the dotted lines are the $10^{\text {th }}$ and the $90^{\text {th }}$ percentiles and the posterior median is given by the solid line.

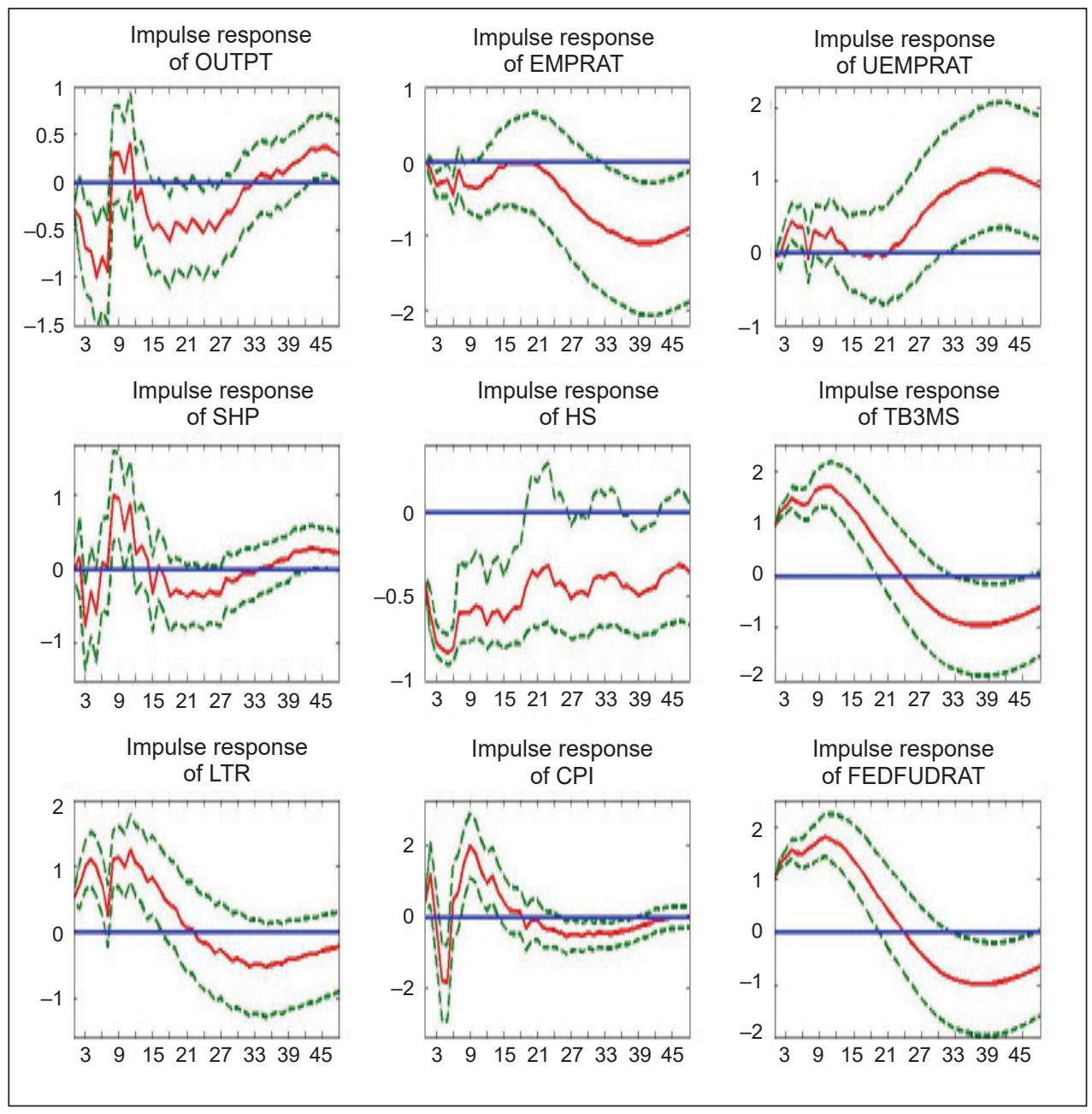

Source: Authors' calculations 
Figure 3 | The Canada impulse response functions to Policy Rate, (POLICYRAT), generated from FAVAR ( $Y=$ POLICYRAT, 3 factors); the dotted lines are the $10^{\text {th }}$ and the $90^{\text {th }}$ percentiles and the posterior median is given by the solid line.

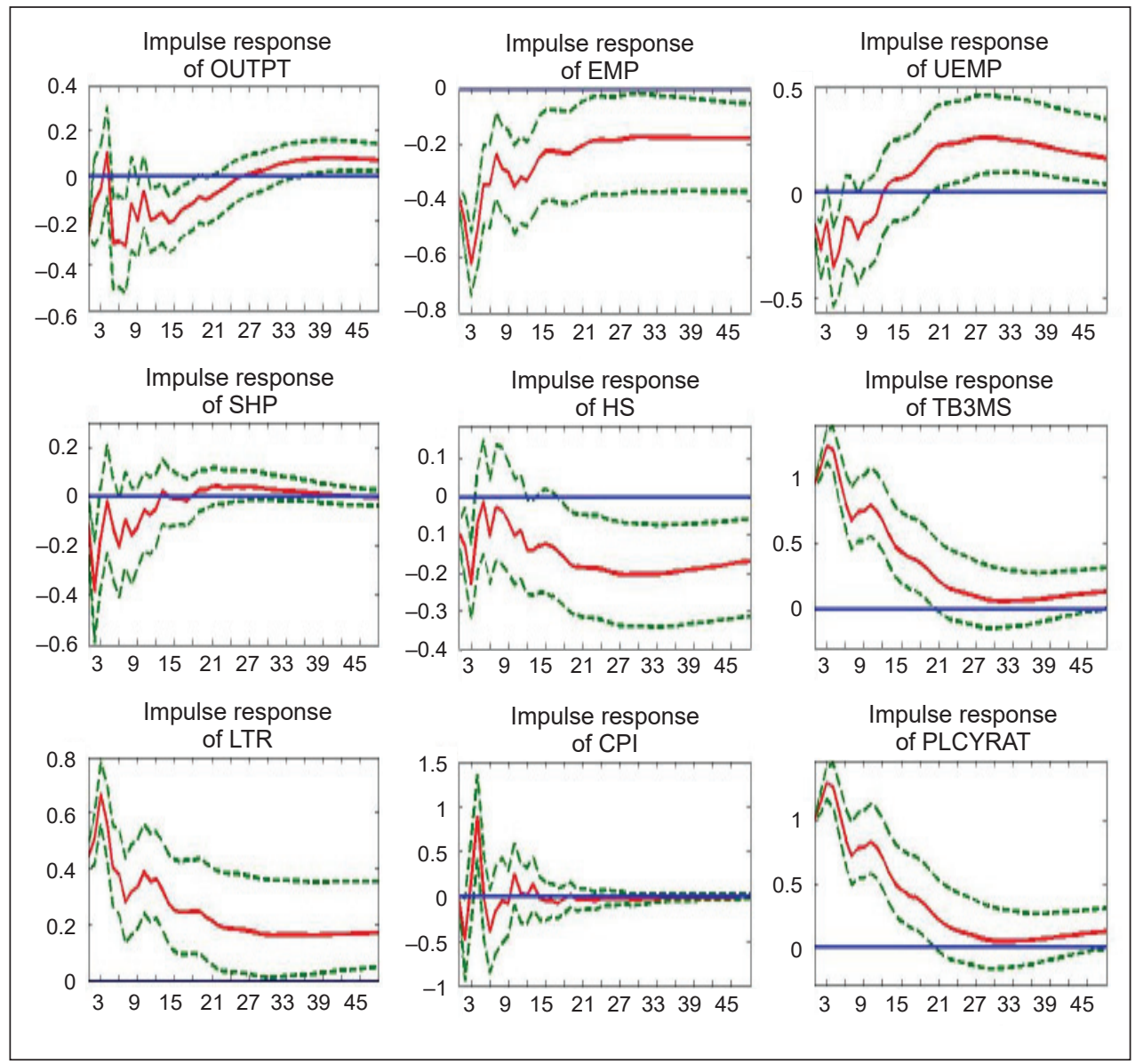

Source: Authors' calculations 
Figure 4 | The Canada impulse response functions to the Policy Rate (POLICYRAT), generated from FAVAR ( $Y=$ POLICYRAT, 5 factors); the dotted lines are the $10^{\text {th }}$ and the $90^{\text {th }}$ percentiles and the posterior median is given by the solid line.

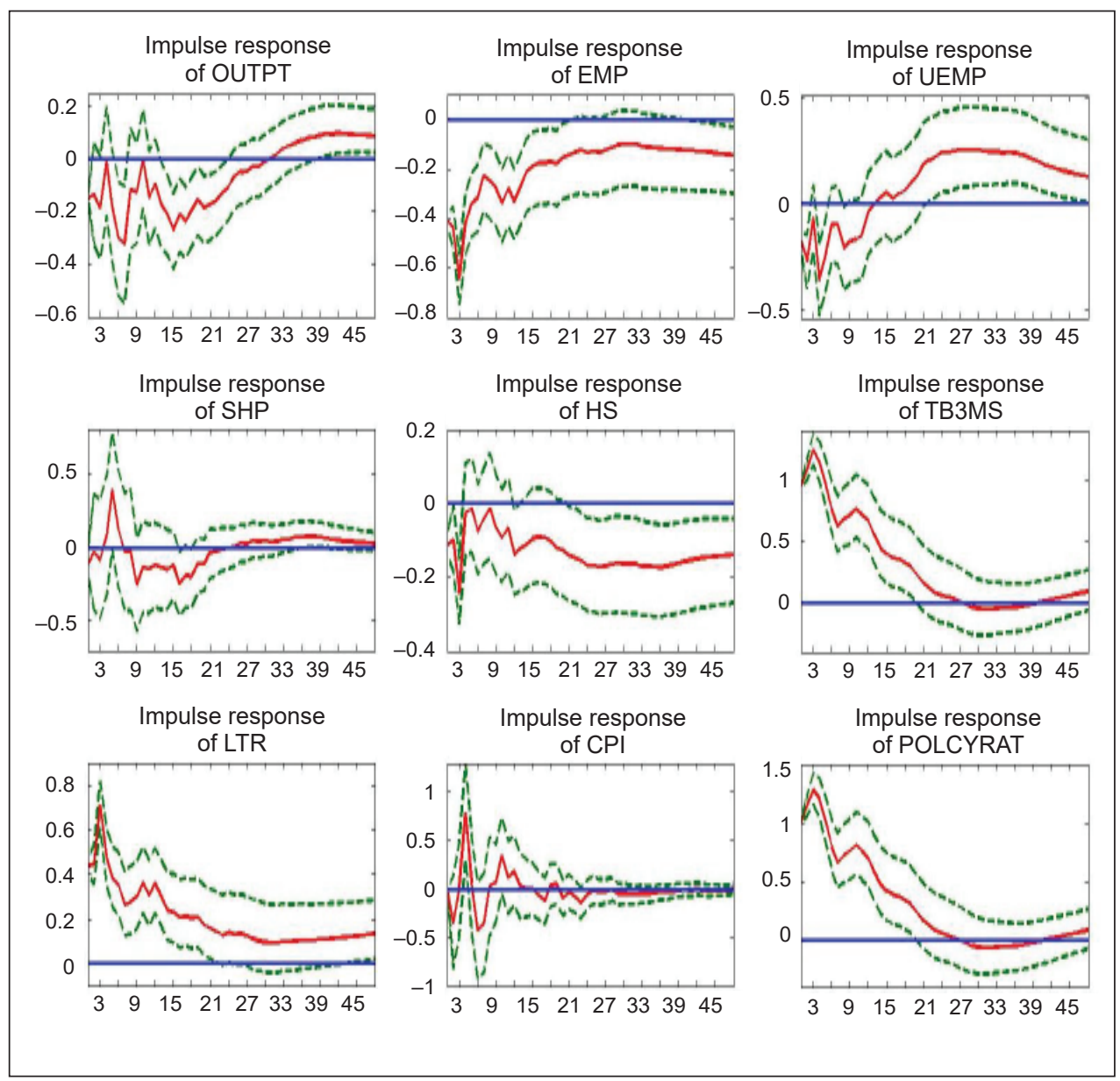

Source: Authors' calculations 
Figure 5 | The UK impulse response functions to the Official Bank Rate (EOBR), generated from FAVAR ( $Y=E O B R, 3$ factors); the dotted lines are the $10^{\text {th }}$ and the $90^{\text {th }}$ percentiles and the posterior median is given by the solid line.

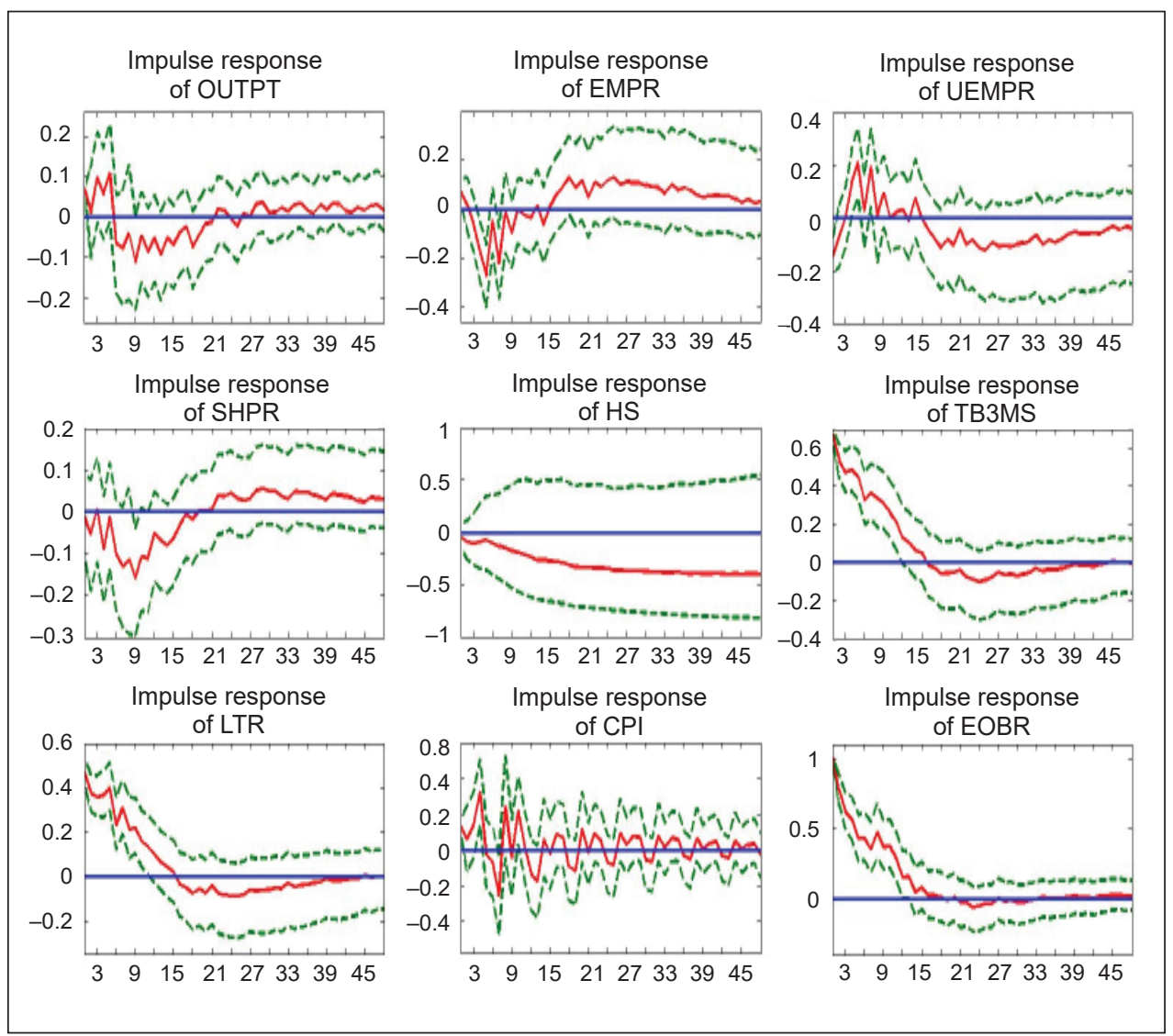

Source: Authors' calculations 
Figure 6 | The UK impulse response functions to Official Bank Rate (EOBR), generated from FAVAR ( $Y=E O B R, 5$ factors), the dotted lines are the $10^{\text {th }}$ and the $90^{\text {th }}$ percentiles and the posterior median is given by the solid line.

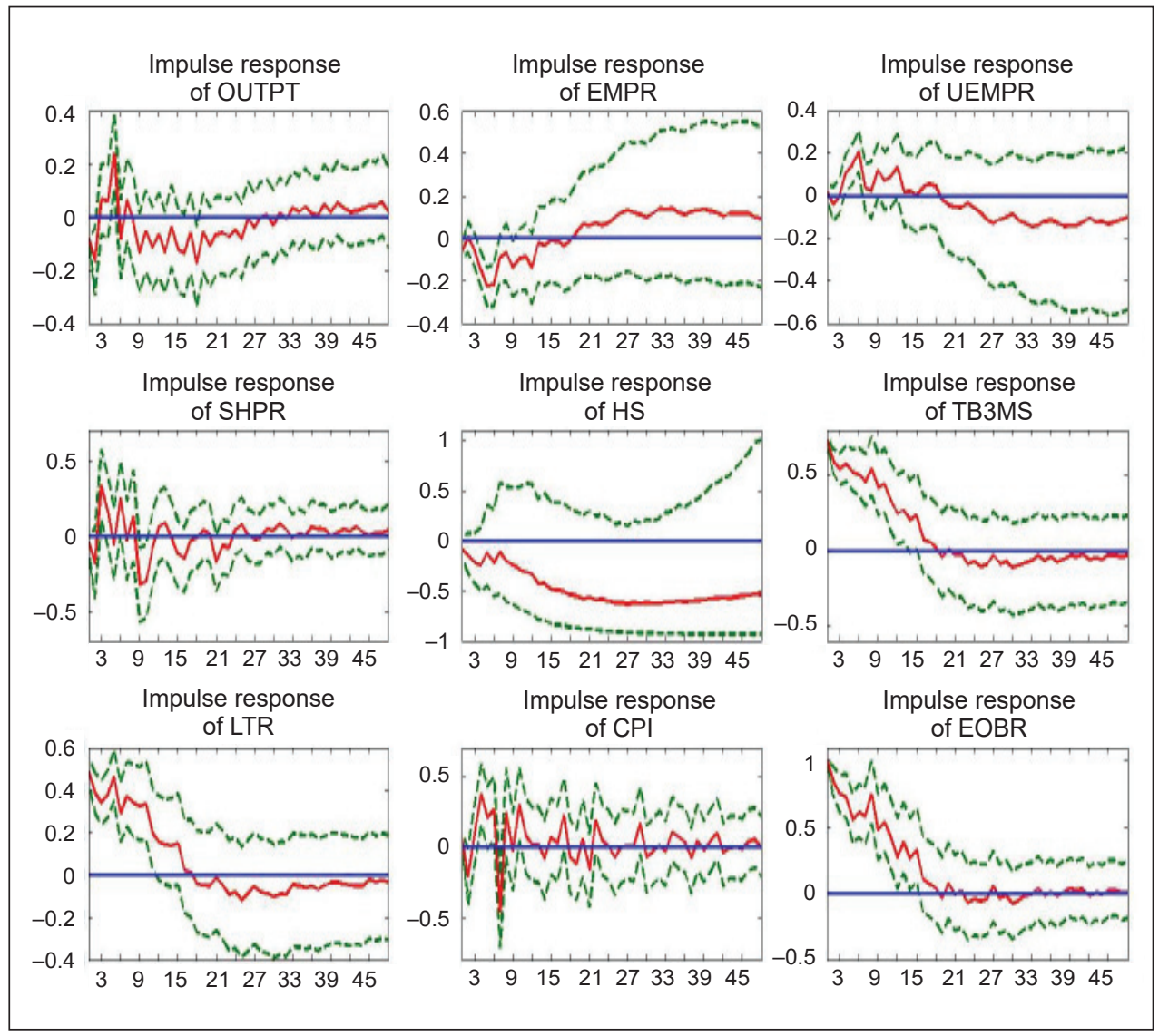

Source: Authors' calculations 


\section{References}

Ang, A., Boivin, J., Dong, S., Loo-Kung, R. (2011). Monetary Policy Shifts and the Term Structure. The Review of Economic Studies, 78(2), 429-457, https://doi.org/10.1093/restud/rdq006

Bańbura, M., Giannone, D., Reichlin, L. (2010). Large Bayesian Vector Auto Regressions. Journal of Applied Econometrics, 25(1), 71-92, https://doi.org/10.1002/jae.1137

Bernanke, B., Gertler, M. (1995). Inside the Black Box: The Credit Channel of Monetary Policy Transmission. Journal of Economic Perspectives, 9(4), 27-48, https://doi.org/10.1257/ jep.9.4.27

Bernanke, B. S., Boivin, J., Eliasz, P. (2005). Measuring the Effects of Monetary Policy: A FactorAugmented Vector Autoregressive (Favar) Approach. The Quarterly Journal of Economics, 120(1), 387-422, https://doi.org/10.1162/0033553053327452

Bils, M., Klenow, P. J., Malin, B. A. (2012). Reset Price Inflation and the Impact of Monetary Policy Shocks. The American Economic Review, 102(6), 2798-2825, https://doi.org/10.1257/ aer.102.6.2798

Bishop, J., Tulip, P. (2017). Anticipatory Monetary Policy and the 'Price Puzzle': Reserve Bank of Australia, https://doi.org/10.2139/ssrn.2971775

Bjørnland, H. C., Halvorsen, J. I. (2014). How Does Monetary Policy Respond to Exchange Rate Movements? New International Evidence. Oxford Bulletin of Economics and Statistics, 76(2), 208-232, https://doi.org/10.1111/obes.12014

Bjørnland, H. C., Jacobsen, D. H. (2010). The Role of House Prices in the Monetary Policy Transmission Mechanism in Small Open Economies. Journal of Financial Stability, 6(4), 218-229, https://doi.org/10.1016/j.jfs.2010.02.001

Bjørnland, H. C., Leitemo, K. (2009). Identifying the Interdependence Between us Monetary Policy and the Stock Market. Journal of Monetary Economics, 56(2), 275-282, https://doi. org/10.1016/j.jmoneco.2008.12.001

Boivin, J., Giannoni, M. P. (2006). Has Monetary Policy Become More Effective? The Review of Economics and Statistics, 88(3), 445-462, https://doi.org/10.1162/rest.88.3.445

Breitung, J., Eickmeier, S. (2006). Dynamic Factor Models. Allgemeines Statistisches Archiv, 90, 27-42. doi:10.1007/s10182-006-0219-z

Bruno, V., Shin, H. S. (2015). Capital Flows and the Risk-Taking Channel of Monetary Policy. Journal of Monetary Economics, 71, 119-132, https://doi.org/10.1016/j. jmoneco.2014.11.011

Castelnuovo, E., Surico, P. (2010). Monetary Policy, Inflation Expectations and the Price Puzzle. The Economic Journal, 120, 1262-1283, https://doi.org/10.1111/j.1468-0297.2010.02368.x

Christiano, L. J., Eichenbaum, M., Evans, C. L. (1999). Monetary Policy Shocks: What Have We Learned and to What End? Handbook of Macroeconomics, 1, 65-148, https://doi. org/10.1016/s1574-0048(99)01005-8

Claessens, S. (2009). The Financial Crisis and Financial Nationalism. Effective Crisis Response and Openness: Implications for the Trading System, CEPR, 263-283.

Cogley, T., Sargent, T. J. (2005). Drifts and Volatilities: Monetary Policies and Outcomes in the Post WWII US. Review of Economic Dynamics, 8(2), 262-302, https://doi. org/10.1016/j.red.2004.10.009

Coibion, O. (2012). Are the Effects of Monetary Policy Shocks Big or Small? American Economic Journal: Macroeconomics, 4, 1-32, https://doi.org/10.1257/mac.4.2.1 
Gerlach, S., Smets, F. (1995). The Monetary Transmission Mechanism: Evidence From The G-7 Countries, Bank for International Settlements, https://doi.org/10.2139/ssrn.868427

Geweke, J. (1977). The Dynamic Factor Analysis of Economic Time Series. Latent Variables in SocioEconomic Models.

Justiniano, A., Primiceri, G. E. (2008). The Time-Varying Volatility of Macroeconomic Fluctuations. The American Economic Review, 98(3), 604-641, https://doi.org/10.1257/ aer.98.3.604

Kazi, I. A., Wagan, H., Akbar, F. (2013). The Changing International Transmission of us Monetary Policy Shocks: Is There Evidence of Contagion Effect on OECD Countries. Economic Modelling, 30, 90-116, https://doi.org/10.1016/j.econmod.2012.07.020

Korenok, O., Radchenko, S. (2004). Monetary Policy Effect on the Business Cycle Fluctuations: Output vs. Index Measures of the Cycle. EconWPA, Series (0409015).

Korobilis, D. (2013). Assessing the Transmission of Monetary Policy Using Time-varying Parameter Dynamic Factor Models. Oxford Bulletin of Economics and Statistics, 75(2), 157-179, https://doi.org/10.1111/j.1468-0084.2011.00687.x

Lagana, G., Mountford, A. (2005). Measuring Monetary Policy in the UK: A FactorAugmented Vector Autoregression Model Approach. The Manchester School, 73, 77-98. Doi:10.1111/J.1467-9957.2005.00462.X

Lamb, T. (2016). US Likely to Resume Monetary Policy Tightening: Feature-Investing 2016. Money Marketing, 2016(Dec 2016), 20.

Lanne, M., Luoto, J. (2016). Data-Driven Inference on Sign Restrictions in Bayesian Structural Vector Autoregression: Department of Economics and Business Economics, Aarhus University.

Mishkin, F. S. (2007). Housing and the Monetary Transmission Mechanism, National Bureau of Economic Research, https://doi.org/10.3386/w13518

Nocera, A., Roma, M. (2017). House Prices and Monetary Policy in the Euro Area: Evidence from Structural VARs, European Central Bank.

Primiceri, G. E. (2005). Time Varying Structural Vector Autoregressions and Monetary Policy. The Review of Economic Studies, 72(3), 821-852, https://doi. org/10.1111/j.1467-937x.2005.00353.x

Rabanal, P. (2007). Does Inflation Increase after a Monetary Policy Tightening? Answers Based on an Estimated Dsge Model. Journal of Economic Dynamics and Control, 31(3), 906-937, https://doi.org/10.1016/j.jedc.2006.01.008

Romer CD, Romer DH. (2004). A New Measure of Monetary Shocks: Derivation and Implications, American Economic Review 94(4), 1055-1084, https://doi.org/10.1257/0002828042002651

Sims, C. A. (1980). Macroeconomics and Reality. Econometrica: Journal of the Econometric Society, 48(1), 1-1, https://doi.org/10.2307/1912017

Sims, C. A. (1992). Interpreting the Macroeconomic Time Series Facts: The Effects of Monetary Policy. European Economic Review, 36(5), 975-1000, https://doi. org/10.1016/0014-2921(92)90041-T

Sims, C. A., Zha, T. (2006). Were There Regime Switches in us Monetary Policy? The American Economic Review, 96(1), 54-81, https://doi.org/10.1257/000282806776157678

Stock, J. H., Watson, M. W. (2002). Forecasting Using Principal Components from a Large Number of Predictors. Journal of the American Statistical Association, 97(460), 1167-1179, https://doi.org/10.1198/016214502388618960 
Stock, J. H., Watson, M. W. (2005). Implications of Dynamic Factor Models for VAR analysis, National Bureau of Economic Research, https://doi.org/10.3386/w11467

Stock, J. H., Watson, M. W. (2016). Dynamic Factor Models, Factor-Augmented Vector Autoregressions, and Structural Vector Autoregressions in Macroeconomics. Handbook of Macroeconomics, 2, 415-525, https://doi.org/10.1016/bs.hesmac.2016.04.002 